\title{
Editorial Announcement: Electronic submission of papers
}

New Year means changes. Last year, in January 2008, our journal's title changed from Le Lait to Dairy Science $\mathcal{E}$ Technology [1]. This change was motivated by the fact that most of the papers published in Le Lait for more than a decade and all papers since 2005 have been written in English.

Further changes are planned for 2009. We are happy to announce that electronic submission of papers will be available from mid-February via the widely used Editorial Manager system, at http://www.editorialmanager.com/dst/. This change of the submission process will facilitate access to manuscripts by authors, reviewers and members of the Editorial Board, and will lead to a smoother reviewing process. The Guide for authors will be updated concomitantly.

The aims and scope of Dairy Science $\mathcal{E}$ Technology remain unchanged. Dairy Science $\mathcal{E}$ Technology aims to bring together the latest results of fundamental and applied research on the microbiology, biochemistry and physico-chemical properties of milk and dairy products, on the effect of processing on the functional and nutritional quality of dairy products, with a special interest in the factors that promote human health in dairy products.

Editors gratefully acknowledge the scientists for their time, effort and professionalism that they have shown in serving as reviewers for Dairy Science $\mathcal{E}$ Technology in 2008.

Anne Thierry

Editor-in-Chief

[1] J.-L. Maubois, New name for Le Lait, Lait 87 (2007) 489. 